3. Toda K, Fujita T, Domae K, Shimahara Y, Kobayashi J, Nakatani T. Late aortic insufficiency related to poor prognosis during left ventricular assist device support. Ann Thorac Surg. 2011;92:929-34.

4. D’Ancona G, Pasic M, Buz S, Drews T, Dreysse S, Hetzer R, et al. TAVI for pure aortic valve insufficiency in a patient with a left ventricular assist device. Ann Thorac Surg. 2012;93:e89-91.

5. Santini F, Forni A, Dandale R, Ribichini F, Rossi A, Franchi G, et al. First successful management of aortic valve insufficiency associated with HeartMate II left ventricular assist device support by transfemoral Core-
Valve implantation: the Columbus's egg? JACC Cardiovasc Interv. 2012;5 $114-5$.

6. Roy DA, Schaefer U, Guetta V, Hildick-Smith D, Möllmann H, Dumonteil N, et al Transcatheter aortic valve implantation for pure severe native aortic valve regurgitation. J Am Coll Cardiol. 2013;61:1577-84

7. Parikh KS, Mehrotra AK, Russo MJ, Lang RM, Anderson A, Jeevanandam V, et al Percutaneous transcatheter aortic valve closure successfully treats left ventricular assist device-associated aortic insufficiency and improves cardiac hemodynamics. JACC Cardiovasc Interv. 2013:6:84-9.

\title{
Potential myocardial regeneration with CorMatrix ECM: A case report
}

\author{
Bobby Yanagawa, MD, PhD, Vivek Rao, MD, PhD, Terrence M. Yau, MD, MSc, and \\ Robert J. Cusimano, MD, Toronto, Ontario, Canada
}

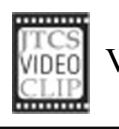

Video clip is available online.

Pericardial and polytetrafluoroethylene patches are currently the most commonly used materials for intraventricular repair but are limited by calcification and retraction. The extracellular matrix (ECM) biomaterial CorMatrix ECM (CorMatrix Cardiovascular, Inc, Roswell, Ga) is an absorbable tissue scaffold synthesized from decellularized porcine small intestinal submucosa that is rich in collagen, glycosaminoglycans, and growth factors. Furthermore, in experimental models of myocardial infarction and ventricular repair, ECM patches have been shown to stimulate infiltration of cells, including cardiomyocytes, as well as ECM production. ${ }^{1,2}$

The epicardial application of CorMatrix ECM has been demonstrated to decrease infarct size and scar formation after myocardial infarction. ${ }^{3}$ We have previously studied the operative safety of the use of CorMatrix ECM for left ventricular aneurysm repair and ventricular septal defect repairs, with no primary repair failures. ${ }^{4}$ Here we report a case of ventricular false aneurysm repair with

\footnotetext{
From the Division of Cardiovascular Surgery, University Health Network, Department of Surgery, University of Toronto, Toronto, Ontario, Canada.

Disclosures: V.R. is a consultant for, is on the Medical Advisory Committee of the Board of Directors of, and receives compensation in the form of stock options from CorMatrix Cardiovascular, Inc, Roswell, Ga. All other authors have nothing to disclose with regard to commercial support.

Received for publication Nov 17, 2013; accepted for publication Dec 4, 2013; available ahead of print Feb 14, 2014.

Address for reprints: Robert J. Cusimano, MD, The Toronto General Hospital, 200 Elizabeth St, 4N-468 Toronto, ON M5G 2C4, Canada (E-mail: robert.cusimano@ uhn.ca).

J Thorac Cardiovasc Surg 2014;147:e41-3

$0022-5223 / \$ 36.00$

Copyright (C) 2014 by The American Association for Thoracic Surgery

http://dx.doi.org/10.1016/j.jtcvs.2013.12.012
}

CorMatrix ECM, which resulted in improvement of ventricular contractile activity at 1-year follow-up.

\section{CLINICAL SUMMARY}

A 75-year-old female patient underwent 3-vessel coronary artery bypass grafting 9 years before the index visit, then 3 years before the index visit had an acute infarction with ventricular rupture. She underwent sutureless repair of a false aneurysm with Bioglue (CryoLife, Inc, Kennesaw, $\mathrm{Ga}$ ) closure of the lateral ventricular wall.

The patient reported chest pain and syncope. Angiography revealed a superficial false aneurysm $(54 \times 24 \mathrm{~mm})$ superimposed on a deeper false aneurysm $(72 \times 49 \mathrm{~mm}$; Figure 1, $A$, and Video 1). Transthoracic echocardiography demonstrated inferior and inferolateral hypokinesis of the left ventricle (left ventricular ejection fraction 20\%-40\%), ventricular dilation (left ventricular endsystolic diameter $39 \mathrm{~mm}$ and left ventricular end-diastolic diameter $53 \mathrm{~mm}$ ), mild mitral regurgitation, and large false aneurysms.

The patient underwent CorMatrix ECM false aneurysm repair with femoral cannulation through a left thoracotomy. The false aneurysm was opened under deep hypothermic circulatory arrest $\left(28^{\circ} \mathrm{C}\right)$. The communication between the superficial and deep false aneurysm was approximately $20 \times 20 \mathrm{~mm}$, and the more recent false aneurysm was filled with thrombus. The neck of the old false aneurysm extending from the base of the papillary muscles to the apex was closed with CorMatrix ECM with running 4-0 monofilament suture. The superficial false aneurysm was then closed. The patient was rewarmed and decannulated.

Immediate postoperative echocardiography demonstrated inferolateral and anterolateral mid-to-apical akinesis of the left ventricle (left ventricular ejection fraction $35 \%-45 \%$, left ventricular end-systolic diameter $35 \mathrm{~mm}$, left ventricular end-diastolic diameter $42 \mathrm{~mm}$; Figure 1, $B$ 

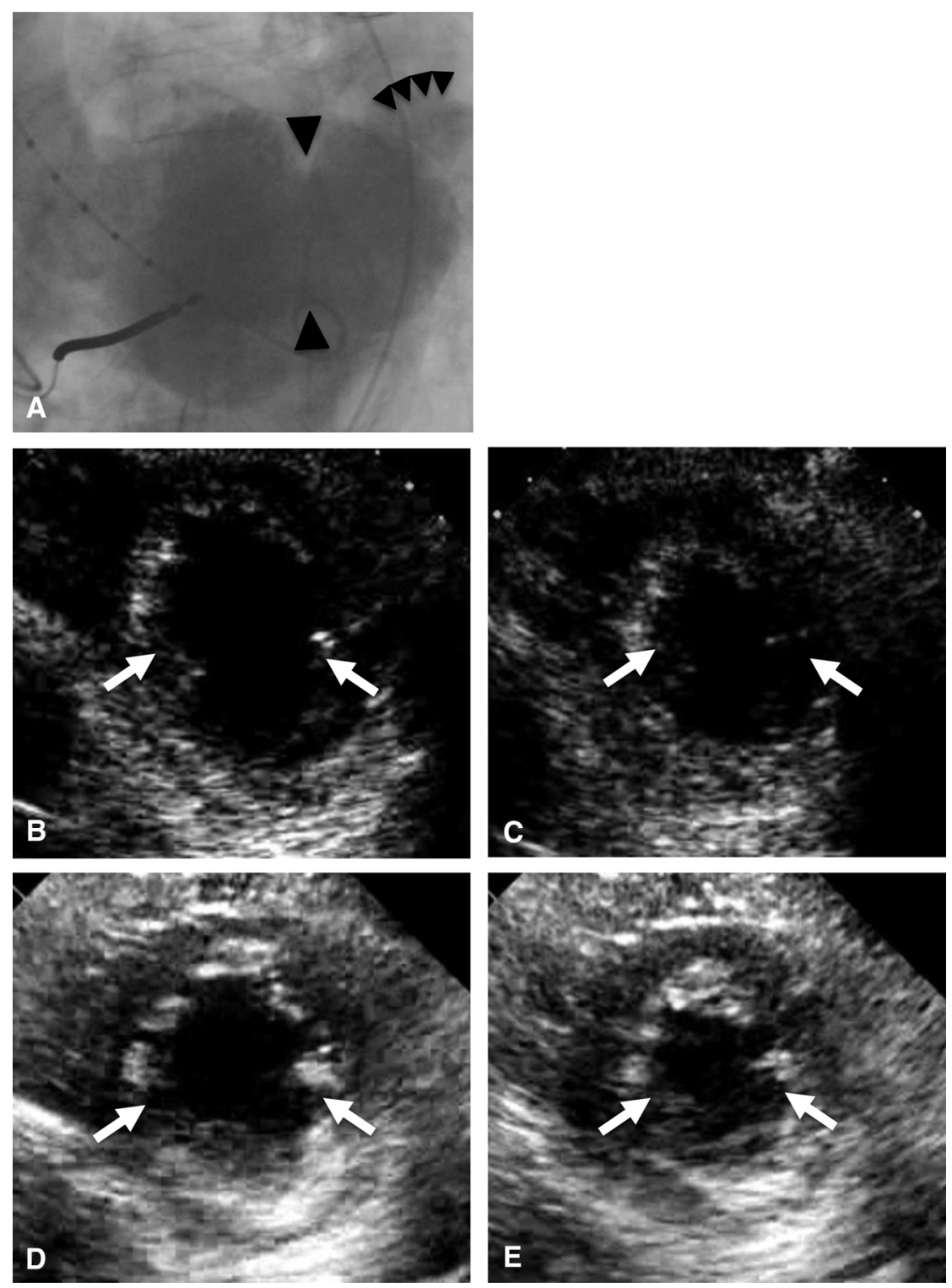

FIGURE 1. Images of CorMatrix ECM intraventricular repair. A, Preoperative angiography demonstrating contrast into the neck of an initial false aneurysm (arrows) and a superimposed false aneurysm (arrowheads). B and C, Postoperative transesophageal echocardiography shows the noncontractile CorMatrix ECM patch (bordered by arrows) in diastole (B) and systole (C). D and E, Transesophageal echocardiograph at 1-year follow-up shows a contractile posterior left ventricular wall in the area of previous CorMatrix ECM patch repair (bordered by arrows) in diastole (C) and systole (D).

and $C$, and Video 2). There was no aneurysm and no patch leak. The patient was discharged from the hospital on postoperative day 10.

At 1 year, the patient had returned to her baseline function without any limitations. Transthoracic echocardiography demonstrated preserved left ventricular end-systolic diameter $(36 \mathrm{~mm})$ and left ventricular end-diastolic diameter $(44 \mathrm{~mm})$ and, to our surprise, restoration of left ventricular function (left ventricular ejection fraction $>60 \%$ ). Furthermore, the area of the CorMatrix ECM patch appeared to have increased wall thickness and synchronous contractile activity (Figure 1, $D$ and $E$, and Video 3).

\section{DISCUSSION}

This is the first clinical report to demonstrate an increase in myocardial wall thickness and ventricular contractile activity with the use of CorMatrix ECM and to document associated clinical improvement. The use of Dacron polyester fabric patch for ventricular aneurysm repair has been associated with early improvement in ventricular function (left ventricular ejection fraction from $28 \%$ to $39 \% ; P=.007) .{ }^{5}$ Generation of myocardial wall thickness and improvement in systolic function, however, have not previously been shown. As mentioned, several experimental studies have demonstrated cellular regeneration with ECM deposition within 
small intestinal submucosa ECM grafts. ${ }^{1-2}$ Although we have not shown cellular regeneration, our findings of contractile activity support the continued use and study of CorMatrix ECM cardiac repair.

\section{References}

1. Robinson KA, Li J, Mathison M, Redkar A, Cui J, Chronos NA, et al. Extracellular matrix scaffold for cardiac repair. Circulation. 2005;112(9 Suppl):I135-43
2. Badylak S, Obermiller J, Geddes L, Matheny R. Extracellular matrix for myocardial repair. Heart Surg Forum. 2003;6:E20-6.

3. Mewhort HE, Turnbull JD, Meijndert HC, Ngu JM, Fedak PW. Epicardial infarct repair with basic fibroblast growth factor-enhanced CorMatrix-ECM biomaterial attenuates postischemic cardiac remodeling. J Thorac Cardiovasc Surg. Epub 2013 Sep 26

4. Yanagawa B, Rao V, Yau TM, Cusimano RJ. Initial experience with intraventricular repair using CorMatrix Extracellular Matrix. Innovations. 2013;8:348-52.

5. Kawata T, Kitamura S, Kawachi K, Morita R, Yoshida Y, Hasegawa J. Systolic and diastolic function after patch reconstruction of left ventricular aneurysms. Ann Thorac Surg. 1995;59:403-7.

\title{
Staged total aortic hybrid repair for DeBakey type I dissection: Report of a case
}

\author{
Marco Di Eusanio, MD, PhD, Paolo Berretta, MD, Luigi Lovato, MD, and Roberto Di Bartolomeo, MD, \\ Bologna, Italy
}

Open surgical repair for extensive aortic disease represents a great challenge, and staged approaches involving multiple hybrid procedures have emerged as an appealing alternative to conventional open repair. ${ }^{1}$ We report a case of DeBakey type I aortic dissection treated with a total aortic repair through a staged hybrid approach.

\section{CLINICAL SUMMARY}

A 45-year-old man who had undergone a Bentall procedure for an acute DeBakey type I aortic dissection (Figure 1, $A$-C) 7 years previously was referred to our institution. Computed tomographic scan (Figure 1, D-F) documented a chronic postdissection aneurysm of the aortic arch and thoracoabdominal aorta $(70 \mathrm{~mm})$ with proximal entry tears at the brachiocephalic trunk and aortic isthmus. At the descending thoracic aorta, the true lumen was narrow $(4 \mathrm{~mm})$ and circumferentially dissected; multiple reentry tears were located in the distal aorta, and all visceral vessels originated from the true lumen except for the right renal artery. A staged hybrid approach was offered. The patient initially underwent a complete arch replacement with a wide fenestration of the descending intimal flap and elephant trunk construction. The arch vessels were reimplanted by means of the separate graft

\footnotetext{
From the Department of Cardiac Surgery, University of Bologna, Sant'Orsola-Malpighi Hospital, Bologna, Italy.

Disclosures: Authors have nothing to disclose with regard to commercial support.

Received for publication Sept 25, 2013; revisions received Nov 5, 2013; accepted for publication Dec 5, 2013; available ahead of print Feb 7, 2014

Address for reprints: Marco Di Eusanio, MD, PhD, Cardiac Surgery Department, University of Bologna, Sant'Orsola-Malpighi Hospital, Via Massarenti 9, 40128,

Bologna, Italy (E-mail: marco.dieusanio2@unibo.it).

J Thorac Cardiovasc Surg 2014;147:e43-6

$0022-5223 / \$ 36.00$

Copyright (C) 2014 by The American Association for Thoracic Surgery

http://dx.doi.org/10.1016/j.jtcvs.2013.12.005
}

technique with a 28-mm Siena 4-branched aortic graft (Vascutek Ltd, Glasgow, Scotland; Figure 1, G-I). Antegrade selective cerebral perfusion with moderate hypothermia was used for cerebral protection. ${ }^{2}$ Two months later, graft replacement $(28 \mathrm{~mm})$ of the descending thoracic aorta was performed with temporary left heart bypass, sequential clamping, and cerebrospinal fluid drainage for spinal and visceral protection (Figure 1, J-L). Four months later, the patient was readmitted for treatment completion of the residual thoracoabdominal aortic aneurysm. Through a median laparotomy with a transperitoneal approach, the infrarenal abdominal aorta was replaced and the visceral vessels were revascularized with a $28-\mathrm{mm}$ multibranched Coselli thoracoabdominal graft (Vascutek). Selective renal perfusion with cold crystalloid solution was used for renal protection (Figure 2, A-D). During the same hospitalization, endovascular exclusion of the remaining thoracoabdominal aorta was then performed; 2 Valiant Medtronic stent-grafts (34-36 mm) were implanted with a $20 \%$ to $30 \%$ oversizing. Graft-to-graft overlaps of 4 and $3 \mathrm{~cm}$ were achieved in the proximal and distal landing zones, respectively. Cerebrospinal fluid drainage was applied for spinal cord protection. The predischarge computed tomographic scan showed a total aortic replacement with a partially thrombosed false lumen as a result of residual endograft porosity (Figure 2, E-H). All postoperative courses were totally uneventful. At 6-month follow-up, the patient remains well, with unchanged aortic appearances and stable aortic diameters.

\section{DISCUSSION}

Reoperations for extensive open aortic replacement are associated with considerable morbidity and mortality. During the last decades, hybrid and endovascular repair 